\title{
Design of the Heat Conduction Structure Based on the Topology Optimization
}

\author{
Yongcun Zhang, Shutian Liu and Heting Qiao \\ Dalian University of Technology
}

China

\section{Introduction}

The progress toward smaller scales in electronics makes the cooling of integrate circuits become an important issue. The conventional convective cooling method which is feasible and often used to control the temperature of a system becomes impractical because the channels of heat transfer take up too much space for high compacted integrate circuit. Hence, it is necessary to build heat conduct structures with high conductivity materials so that the heat can be collected, transferred and exchanged with external environment automatically and rapidly[1-2]. A key problem is how to design the structures with a rational distribution of high conductive materials, which not only benefits to the temperature control but also can reduce material and manufacturing costs and bring possibilities for further miniaturization.

Studies designing the optimal heat conduction structure have attracted much attention and many achievements have been obtained [1-24], including mathematical models and the corresponding solving methods. For example, Bejan and co-workers put forward a tree-like network construction method based on the constructal theory [1-8], Guo and co-workers proposed some practical design criteria and developed the corresponding optimization methods for the heat conduction structure based on the least dissipation principle of heat transport potential capacity [9-15]. The topology optimization method has also been applied for heat conduction structural optimization [16-22]. In all these cases, the nature of optimization design for heat conduction structures is to build a mathematical model that maximizes or minimizes an objective function (e.g. the thermal performance index) subjected to certain constrains. Thus, it is a key to define a suitable thermal performance index in such an optimization model.

Statistical data show that the failure of real devices with a fraction of $55 \%$ is caused by the high temperature and this fraction increases exponentially with increasing temperature [25, 26]. Thus, the highest temperature is a primary factor that induces the failure of practical cooling structure and should be well controlled. In practice, it is natural to define the highest temperature as an objective function of the optimization model. However, the location of the highest temperature usually changes with the change of material distribution in the topology optimization process and is a discontinuous function of design variables, which may introduce numerical difficulties in optimization. Therefore, instead of a directing optimization of the highest temperature, it is more convenient to define another proper 
thermal performance index as the objective function in an optimization model to accomplish indirectly the goal of minimizing the highest temperature.

In the optimization model of heat conduction structure, the objective function can be selected as

$$
f(\boldsymbol{X})=\int_{\Omega} \frac{1}{2}(-\boldsymbol{q}(\boldsymbol{X}) \nabla T(\boldsymbol{X})) \mathrm{d} \Omega
$$

where $X$ is the design variable used to describe the distribution of material, $q(X)$ is the flux density and $\nabla T(X)$ is the temperature gradient. Using the finite element formulation, Eq. (1) can be also written as

$$
f(\boldsymbol{X})=\boldsymbol{T}^{\mathrm{T}} \boldsymbol{K}(\boldsymbol{X}) \boldsymbol{T}
$$

where $T$ is the global temperature vector and $K(X)$ is the thermal conductivity matrix. Generally, Eq. (1) is defined as the dissipation of heat transport potential capacity (DHTPC) [11], and the least dissipation principle of heat transport potential capacity is presented based on this definition; Eq. (2) is defined as the heat dissipation efficiency[17,18], which is the objective function of the heat conduction topology optimization.

Using the DHTPC (or the heat dissipation efficiency) as a thermal performance index, some good design results have been obtained. However, this index can only tell us the heat dissipative capability rather than the highest temperature. How much difference between DHTPC and the present design goal, that is, the control of the highest temperature? Is there any better thermal performance index? Answers to these questions are the motivation of this study.

Firstly, the difference between the DHTPC and the present design goal is evaluated by a one-dimensional heat conduction problem for a planar plate exchanger. Then, the geometric average temperature (GAT) is proposed as a new thermal performance index and the corresponding heat conduction optimization model is developed, the validity of optimization model is proved by two example. Finally, some useful conclusions are given.

\section{Heat conduction optimization of the planner plate exchanger}

In many practical cooling structures, a commonly used design criterion is that the highest temperature must not exceed a specified value. However, the optimization objective in many existing heat conduction optimization models is the DHTPC. To evaluate the quality of these exiting models, we compare their results with those obtained from an optimization model with the highest temperature as the objective function. For simplicity, the presented example is a one-dimensional heat conduction problem for a planar plate, which can be solved analytically.

\subsection{Problem description}

A rectangular planar plate exchanger, with length $l$, width $W(W>>l)$ and thickness $t$, is embedded in the heater. The heat generated by heater flows into the exchanger uniformly. The heat flowing into the exchanger is $q^{\prime \prime}$ per unit time and area. Only one side along the width direction of exchanger contacts with a thermostat with a constant temperature $T_{0}$ and others are adiabatic. This problem can be described as a planar heat conduction model with uniform heat source, as shown in Fig. 1. Furthermore, this model can be simplified into a 
one-dimensional heat transfer problem because the thickness $t$ and the internal heat source $q$ do not change along the width direction. The goal is to obtain the optimal heat conduction performance by designing the thickness $t$ along the length direction of exchanger.

Since thermal conductivity is proportional to thickness $t$, the thickness design can be transformed into the conductivity field design. That is to say, the limitation of material, $\int_{0}^{l} t(x) W \mathrm{~d} x=$ const, can be written as the capability of conductivity, $\int_{0}^{l} k(x) \mathrm{d} x=K_{0}$, where $K_{0}$ is a constant. The governing equation of heat conduction in the exchanger can be described as

$$
\begin{aligned}
& q(x)=-k(x) \frac{\mathrm{d} T}{\mathrm{~d} x}, \quad \frac{\mathrm{d} q}{\mathrm{~d} x}+q^{\prime \prime}=0, \quad 0<x<l \\
& T(x=0)=T_{0}, \quad q(x=l)=0
\end{aligned}
$$

where, $k(x)$ is the thermal conductivity, $q(x)$ is the heat flux density and $T(x)$ is the temperature. In addition, the heat flux is assumed to be positive along the $x$ direction. Solving equations (3), we can obtain

$$
q=-q^{\prime \prime}(l-x), \quad T(x)=T_{0}+\int_{0}^{x} \nabla T \mathrm{~d} x=T_{0}+q^{\prime \prime} \int_{0}^{x}(l-x) / k(x) \mathrm{d} x .
$$

Then, the optimization design for the exchanger is to determine the optimal heat conduction performance by designing the conductivity filed under a given integral of thermal conductivity (or material volume) over the design domain. Let $f(k)$ denotes a thermal performance index. The heat conduction optimization problem can be formulated as

$$
\begin{array}{ll}
\text { Find : } & k(x) \\
\min : & f(k) \\
\text { s.t.: } & \int_{0}^{l} k(x) \mathrm{d} x=K_{0}
\end{array}
$$

Using the Lagrange multiplier method, the solution of the thermal conductivity field can be determined by

$$
\delta_{k}(f(k))+\lambda \int_{0}^{l} \delta k \mathrm{~d} x=0, \quad \delta \lambda\left(\int_{0}^{l} k \mathrm{~d} x-K_{0}\right)=0
$$

\subsection{Minimization of the highest temperature}

According to the heat conduction theory, the highest temperature is located on the boundary of $x=l$ and can be written as

$$
T_{\max }(k)=T_{0}+q^{\prime \prime} \int_{0}^{l}(l-x) / k(x) \mathrm{d} x
$$

Substituting Eq. (7) into Eq. (6), we have

$$
\int_{0}^{l}\left[-q^{\prime \prime}(l-x) / k^{2}(x)+\lambda\right] \delta k(x) \mathrm{d} x=0, \quad \int_{0}^{l} k \mathrm{~d} x=K_{0}
$$

The optimal thermal conductivity field $k_{T_{\max }}(x)$ can be obtained by solving Eq. (8), which is 


$$
k_{T_{\max }}(x)=\frac{3 K_{0}}{2 l^{3 / 2}}(l-x)^{1 / 2}
$$

and the corresponding temperature distribution is

$$
T_{T_{\max }}(x)=T_{0}+\frac{4 q^{\prime \prime} l^{3 / 2}}{9 K_{0}}\left(l^{3 / 2}-(l-x)^{3 / 2}\right)
$$

Introducing a dimensionless parameter

$$
\tilde{x}=x / l
$$

the conductivity field and the temperature distribution can be expressed in the dimensionless space as

$$
\tilde{k}_{T_{\max }}(\tilde{x})=\frac{k(x)}{K_{0} / l}=3(1-\tilde{x})^{1 / 2} / 2
$$

and

$$
\widetilde{T}_{T_{\max }}(\widetilde{x})=\frac{T(x)-T_{0}}{q^{\prime \prime} l^{3} / K_{0}}=4\left(1-(1-\tilde{x})^{3 / 2}\right) / 9
$$

where subscript $T_{\max }$ denotes that the optimization objective is to minimize the highest temperature.

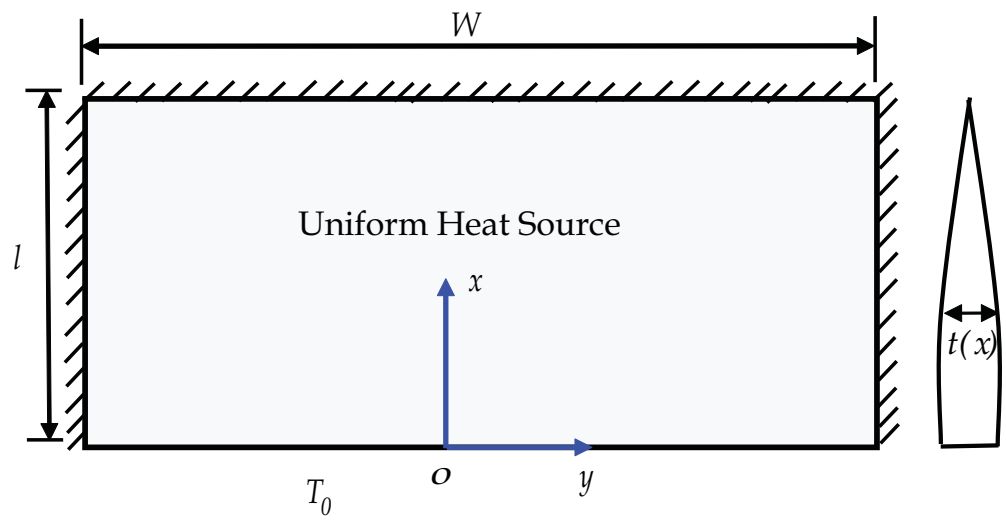

Fig. 1. A theoretical model of a planar plate exchanger

\subsection{Minimization of the dissipation of heat transport potential capacity}

For the planar plate exchanger, the DHTPC can be expressed as

$$
f(k)=\frac{\left(q^{\prime \prime}\right)^{2}}{2} \int_{0}^{l} \frac{(l-x)^{2}}{k} \mathrm{~d} x
$$

When the DHTPC is considered as an optimization objective function, the optimal thermal conductivity field should obey the following necessary conditions 


$$
\int_{0}^{l}\left[-\frac{\left(q^{\prime \prime}\right)^{2}(l-x)^{2}}{2 k^{2}(x)}+\lambda\right] \delta k(x) \mathrm{d} x=0, \quad \int_{0}^{l} k \mathrm{~d} x=K_{0}
$$

The thermal conductivity field can be obtained by solving Eq. (15), which is

$$
k_{\mathrm{dis}}(x)=\frac{2 K_{0}}{l^{2}}(l-x)
$$

and the corresponding temperature distribution is

$$
T_{\text {dis }}(x)=T_{0}+\frac{q^{\prime \prime} l^{2}}{2 K_{0}} x
$$

The dimensionless thermal conductivity field and temperature distribution are

$$
\tilde{k}_{\mathrm{dis}}(\tilde{x})=\frac{k(x)}{K_{0} /(l)}=2(1-\tilde{x})
$$

and

$$
\tilde{T}_{\mathrm{dis}}(\tilde{x})=\frac{T(x)-T_{0}}{q^{\prime \prime} l^{3} / K_{0}}=\tilde{x} / 2
$$

where subscript dis denotes that the optimization objective is to minimize the DHTPC.

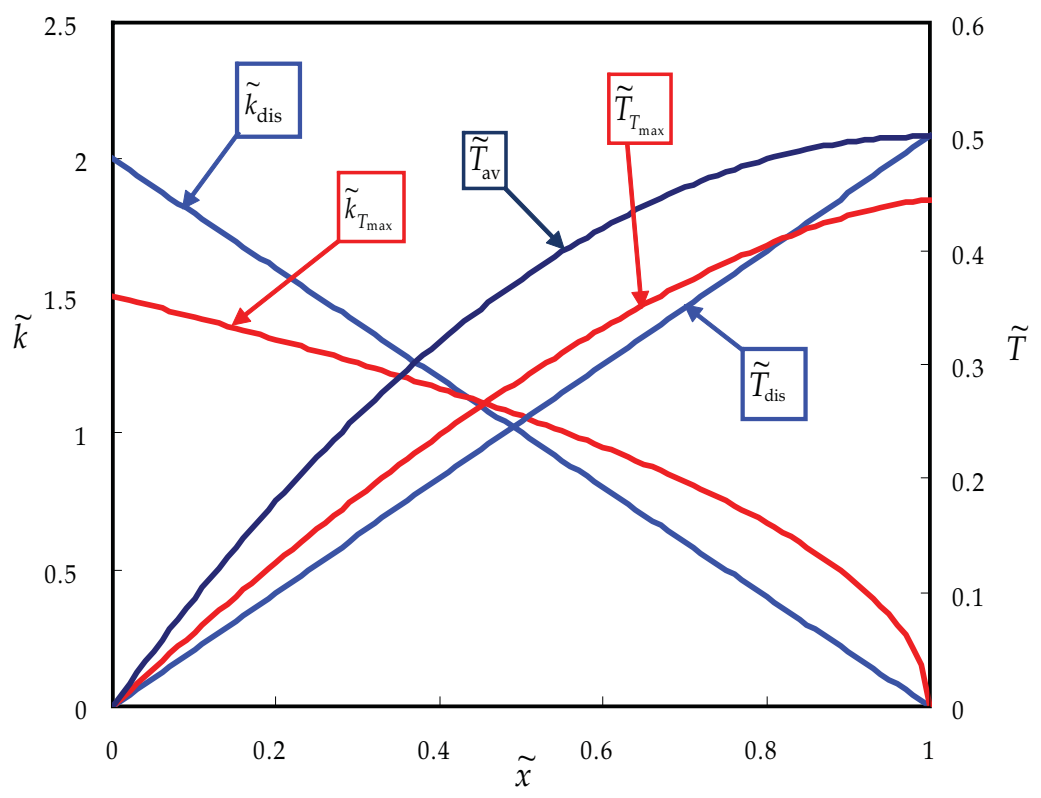

Fig. 2. Comparisons of thermal conductivity fields and temperature distributions from different optimization models. av: the uniform conductivity field; dis: the dissipation of heat transport potential capacity; $T_{\max }$ : the highest temperature 


\subsection{Comparisons of two different optimization models}

The dimensionless thermal conductivity fields and the corresponding dimensionless temperature distributions from the two different optimization models are shown in Fig. 2. To facilitate the comparisons, the temperature distribution with uniformly distributed thermal conductivity (denoted by 'av') is analyzed, which can be expressed as

$$
T_{\mathrm{av}}=T_{0}+\int_{0}^{x} \nabla T \mathrm{~d} x=T_{0}+\frac{q^{\prime \prime} l\left(l x-x^{2} / 2\right)}{K_{0}}
$$

and the corresponding dimensionless temperature distribution is

$$
\tilde{T}_{\mathrm{av}}=\tilde{x}-\tilde{x}^{2} / 2
$$

which is also plotted in Fig. 2. It can be found that the temperature distribution from the model with an objective function of the DHTPC has an obvious reduction in the internal exchanger when compared with the temperature field from the model with a uniform thermal conductivity field. However, these two models give the same highest temperature. In addition, when compared with the model with an objective function of the highest temperature, large differences in thermal conductivity field can be found and the highest temperature increases by $12.5 \%$, which indicates that the optimization model with an objective function of the DHTPC sometimes cannot fulfill the present design goal. Thus, it is necessary to propose new thermal performance indexes for the optimization model.

\section{Optimization model based on the geometric average temperature}

\subsection{Objective function and optimization model}

As mentioned above, the optimal design by the optimization model with DHTPC as an objective function sometimes introduces large errors compared with the present design goal. Furthermore, since the highest temperature is a discontinuous function of design variables, direct optimization of it will bring numerical difficulties. To achieve a good tradeoff between the optimization performance and numerical cost, a new thermal performance index called the geometric average temperature $T_{\text {geoav }}$ is proposed, which can be expressed as

$$
\left.T_{\text {geoav }}=\left(\frac{1}{|\Omega|} \int_{\Omega}(T(\boldsymbol{x}))^{n} \mathrm{~d} \boldsymbol{x}\right)\right)^{1 / n}, x \in \Omega
$$

Where $|\Omega|$ denotes the area (or volume) over the design region. Theoretically, the geometric average temperature is close to the highest temperature when $n$ is infinitely large, i.e. $T_{\text {geoav }} \stackrel{n \rightarrow \infty}{\rightarrow} T_{\max }$. Thus, the geometric average temperature is an appropriate approximation of the highest temperature. The new heat conduction optimization model can be written as

Find : $X=k(x), \quad x \in \Omega$

$$
\begin{array}{ll}
\min : & \left.T_{\text {geoav }}(X)=\left(\frac{1}{|\Omega|} \int_{\Omega}(T(\boldsymbol{x}))^{n} \mathrm{~d} \boldsymbol{x}\right)\right)^{1 / n} \\
\text { s.t.: } \quad \int_{\Omega} k \mathrm{~d} \Omega=K_{0}, \quad K_{0}=\text { const }
\end{array}
$$


Here, the finite element method is used to solve the optimization problem. Suppose that the material is uniformly distributed and has the same conductivity in each element. Then the distribution of material can be described by the different thermal conductivity in each element mesh, which can be expressed by the finite element method

$$
k(x)=k_{e}, \quad x \in \Omega_{e}, \quad e=1,2, \cdots, N e
$$

where $k_{e}(e=1,2, \cdots, N e)$ denotes the thermal conductivity of the $e$-th element, $\Omega_{e} \in \Omega$ the region of the $e$-th element and $N e$ the total number of elements. Then, the temperature and its $n$ power in an element can be written as

$$
\begin{gathered}
T(x)=[N(x)]\{\bar{T}\}, \quad T^{n}(x)=[N(x)]\left\{\bar{T}^{n}\right\} \\
\{\bar{T}\}=\left(T_{1}, T_{2}, \cdots, T_{N \mathrm{p}}\right)^{\mathrm{T}}, \quad\left\{\bar{T}^{n}\right\}=\left[\left(T_{1}\right)^{n},\left(T_{2}\right)^{n}, \cdots,\left(T_{N \mathrm{p}}\right)^{n}\right)^{\mathrm{T}}
\end{gathered}
$$

where $\{\bar{T}\}$ and $\left\{\bar{T}^{n}\right\}$ denote the temperature vector of nodes and the corresponding $n$ power, respectively. $T_{n}\left(n=1,2, \cdots N_{\mathrm{p}}\right)$ is the temperature of the $n$-th node, $N_{\mathrm{p}}$ is the total number of nodes and $[N(x)]$ is the shape function matrix. The node temperature can be solved by the following governing equation

$$
[K]\{\bar{T}\}=\{Q\}
$$

where $\{Q\}$ is the thermal flux vector and $[K]$ is the thermal conductivity matrix which can be assembled by the element thermal conductivity matrix

$$
[K]=\sum_{e=1}^{N e}\left[K_{e}\right], \quad\left[K_{e}\right]=k_{e}\left[K_{e}^{0}\right]
$$

where $\left[K_{e}^{0}\right]$ is the $e$-th element thermal conductivity matrix with a unit thermal conductivity. The geometric average temperature can be rewritten as

$$
T_{\text {geoav }}=\left([B]\left\{\bar{T}^{n}\right\}\right)^{1 / n}, \quad[B]=\frac{1}{|\Omega|} \int_{\Omega}[N(x)] \mathrm{d} x
$$

Therefore, the heat conduction optimization problem can be expressed as

$$
\begin{array}{ll}
\text { Find : } \boldsymbol{X}=\left(k_{1}, k_{2}, \cdots k_{N e}\right)^{\mathrm{T}} \\
\min : \quad T_{\text {geoav }}(\boldsymbol{X})=\left([B]\left\{\bar{T}^{n}\right\}\right)^{1 / n} \\
\text { s.t.: } \quad \sum_{e=1}^{N e} k_{e} V_{e}=K_{0}, \quad V_{e}=\left|\Omega_{e}\right|
\end{array}
$$

The feasible direction method was employed to find the optimal solution. The sensitivity of the objective function (the geometric average temperature) can be expressed as

$$
\frac{\partial T_{\text {geoav }}}{\partial k_{e}}=\frac{1}{n}\left([B]\left\{\bar{T}^{n}\right\}\right)^{-(n-1) / n}[B] \frac{\partial}{\partial k_{e}}\left\{\bar{T}^{n}\right\}
$$

where 


$$
\frac{\partial}{\partial k_{e}}\left\{\bar{T}^{n}\right\}=\operatorname{diag}\left(n T_{1}^{(n-1)}, n T_{2}^{(n-1)}, \cdots, n T_{N \mathrm{p}}^{(n-1)}\right)\left\{\frac{\partial \bar{T}}{\partial k_{e}}\right\}
$$

and

$$
\left\{\frac{\partial \bar{T}}{\partial k_{e}}\right\}=-[K]^{-1}\left(\frac{\partial}{\partial k_{e}}[K]\right)\{\bar{T}\}=-[K]^{-1}\left[K_{e}^{0}\right]\{\bar{T}\}
$$

\subsection{Example 1}

The planar plate exchanger is analyzed again by the new optimization model (23), in which the one-dimensional heat conduction element with two nodes was used to mesh the design domain and the feasible direction method was employed to find the optimal solution. The obtained thermal conductivity field (material distribution) and the corresponding temperature distribution are shown in Fig. 3. To facilitate comparisons, the solutions of the optimization models with the DHPC and the highest temperature as objective functions are also shown in Fig. 3. It can be seen that the thermal conductivity field and the temperature distribution are close to the present design goal (the solution of minimizing the highest temperature) when the power index $n$ is larger than 16. Thus, the geometric average temperature is an ideal thermal performance index. The new optimization model with the geometric average temperature as the objective function is a more accurate description for the design goal than that with the DHTPC as the objective function. The results obtained from the convectional optimization model with the DHTPC as the objective function is equal to that from the new optimization model when the power index $n$ is 1 . With the increasing

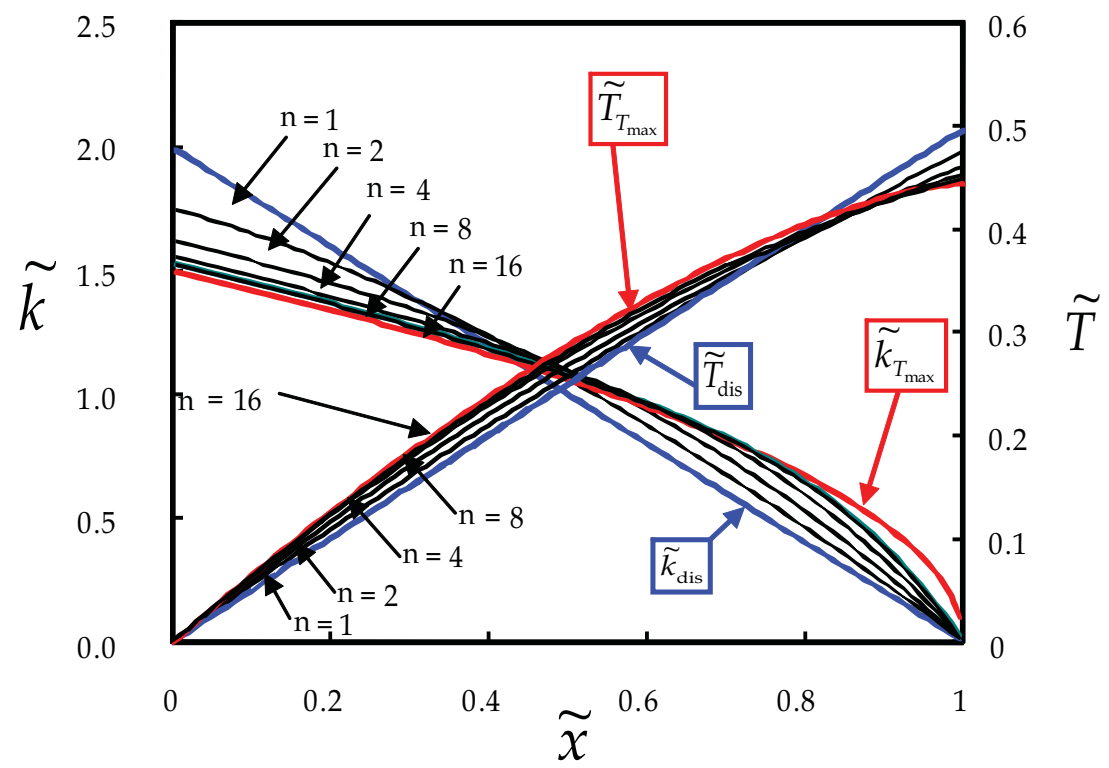

Fig. 3. The solutions of the optimization model based on the geometric average temperature with different power indexes. Results from other models are also shown for comparison 
of power index $n$, the thermal conductivity field and temperature field obtained by the new model is rapidly close to the ideal design. The change of the corresponding highest temperature with the increasing power index $n$ is shown in Fig. 4. Since the approximate level tends to stabilize with the increasing power index $n$, an appropriate value is required to select for the power index $n$ in a practical optimization process.

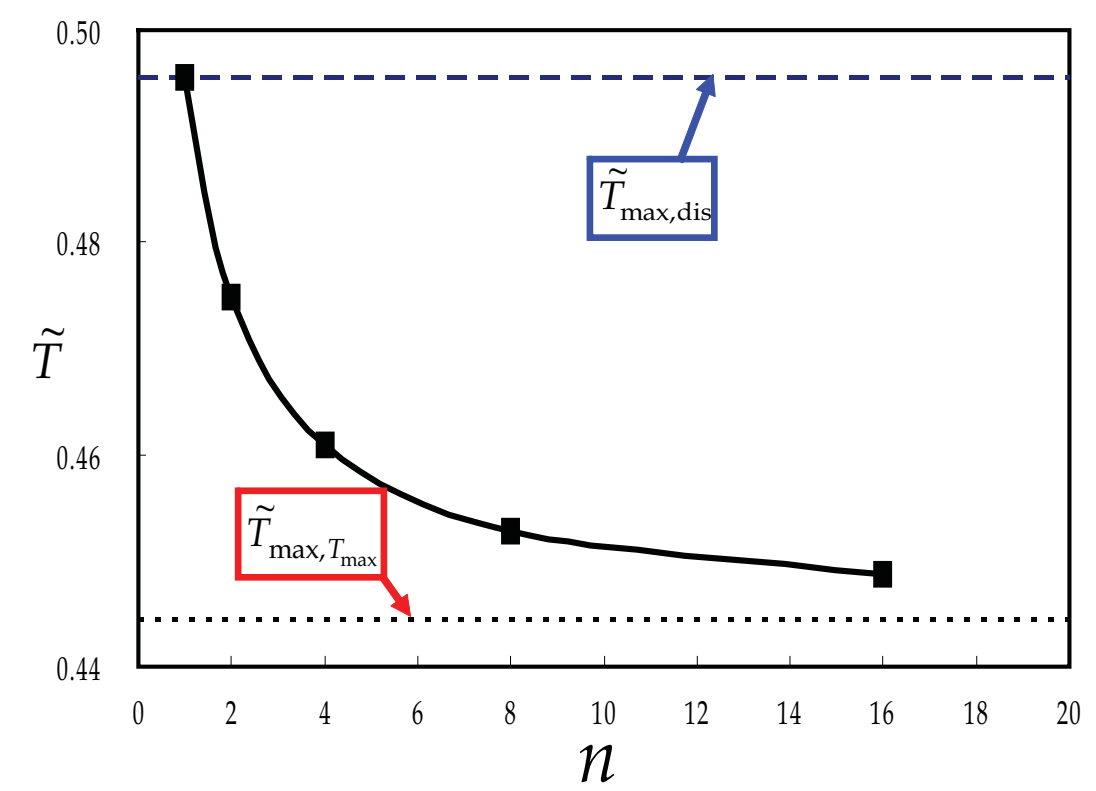

Fig. 4. The highest temperature obtained by the optimization model based on the geometric average temperature versus the power index $n$. $\tilde{T}_{\max , \mathrm{dis}}$ and $\tilde{T}_{\max , T_{\max }}$ denote the corresponding highest temperatures of the optimal solution of optimization models with the DHTPC and the highest temperature as the objective function, respectively

\subsection{Example 2}

To demonstrate the difference between these two objective functions used in the topology optimization method, a thermal structure with five heat sources is presented as an example in this section.

A square planar plate, with dimension $50 \mathrm{~mm} \times 50 \mathrm{~mm}$, is meshed by $50 \times 50$ discrete rectangular elements. Temperature is 0 centigrade around the boundary, and five heat sources are set symmetrically in the centre and around the plate with heat flux $1 \mathrm{~kW} / \mathrm{m}^{2}$. Material with thermal conductivity $k_{p}=200 \mathrm{~W} /(\mathrm{m} \cdot \mathrm{K})$ is used to filled this structure, and the volume fraction $V_{\mathrm{f}}$ of this high heat-conductivity material is given to be 0.35 , as shown in fig. 5 .

A model using minimum heat dissipation as its objective function is adopted to solve this problem, and its structural topology result is shown in fig. 6.(a), corresponding the contours of temperature distribution and temperature gradient are shown in fig. 6.(b) and fig. 6.(c) respectively. Likewise, the topology result of a model using geometric average temperature as its objective function is shown in fig. 7. 


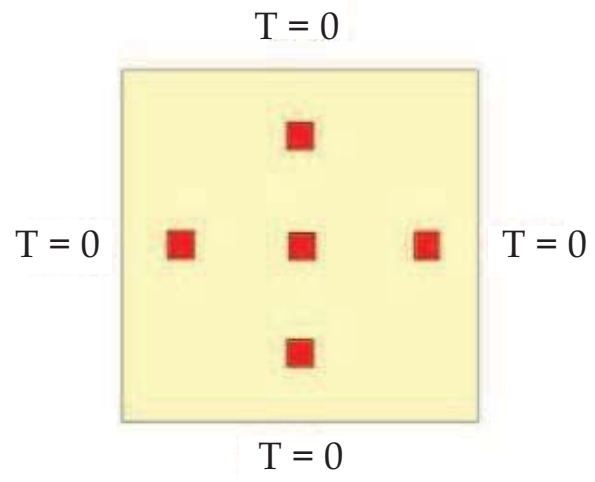

Fig. 5. Initial design domain with five heat sources

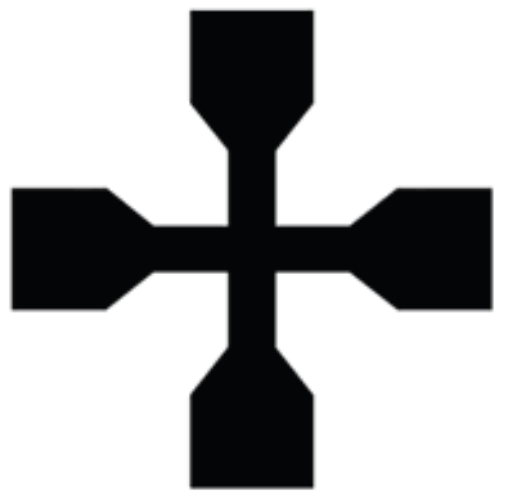

(a)

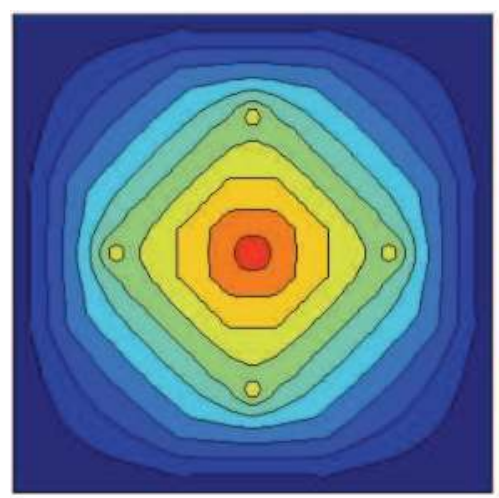

(b)

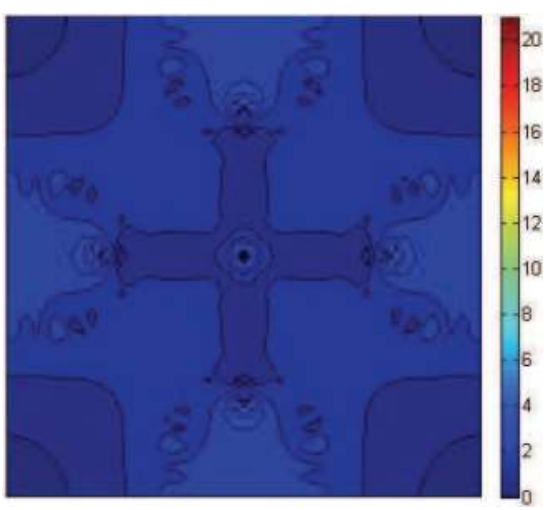

(c)

Fig. 6. (a) The optimal design generated from the optimization model 1 (b) the temperature distribution isoline map (c) the temperature gradient isoline map 


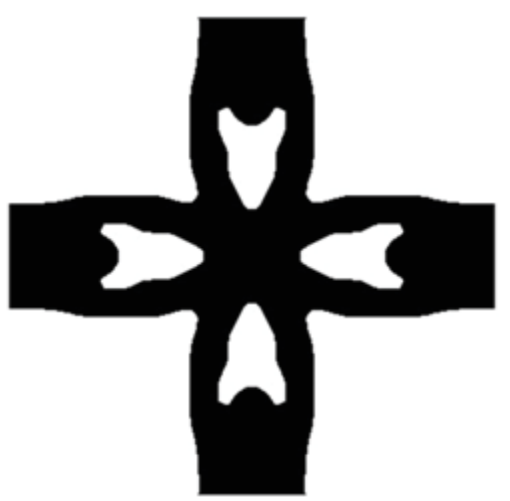

(a)

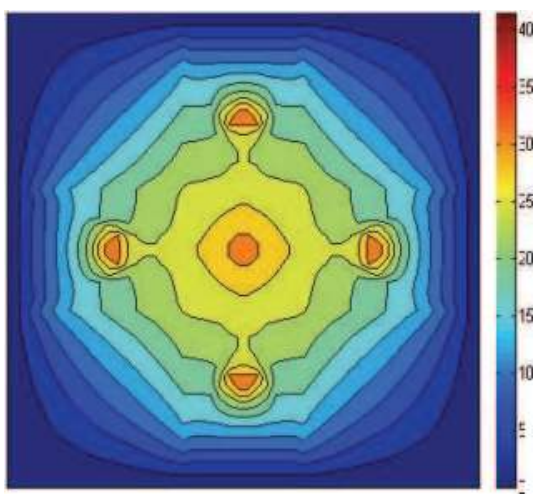

(b)

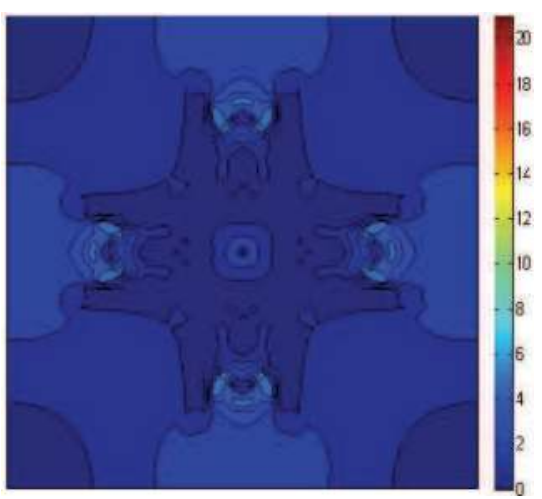

(c)

Fig. 7. (a) The optimal design generated from the optimization model 3 (b) the temperature distribution isoline map (c) the temperature gradient isoline map

\begin{tabular}{llll}
\hline $\begin{array}{l}\text { Optimization } \\
\text { model }\end{array}$ & $\begin{array}{l}\text { Heat } \\
\text { dissipation }\end{array}$ & $\begin{array}{l}\text { Maximum } \\
\text { temperature } \\
\left({ }^{\circ} \mathrm{C}\right)\end{array}$ & $\begin{array}{l}\text { Maximum } \\
\text { temperature } \\
\text { gradient }\end{array}$ \\
\hline Model 1 & $5.43 \mathrm{e} 5$ & 37.81 & 4.24 \\
\hline Model 2 & $6.23 \mathrm{e} 5$ & 33.72 & 6.71 \\
\hline
\end{tabular}

Table 1. Results of the different objective

As shown in Fig. 6-7, these two different topology optimization models obtain entirely different topology results. Using minimum heat dissipation as objective function, the result shows that the high-heat conductivity material connects the central heat source with surrounding heat sources directly and then extend to the outer thermal edge, as shown in fig. 4.(a). This kind of heat transfer path will cause the temperature of the central heat source much higher than the temperature of the surrounding heat sources. On the contrary, using geometric average temperature as objective function, the result shows that, instead of 
connecting the central heat source with surrounding heat sources directly, the high-heat conductivity material bypass the surrounding heat sources and then connect to the outer thermal edge, as shown in fig. 6.(a). This kind of heat transfer path will cause the temperature of the central heat source and the surrounding heat sources equal to the maximum temperature simultaneously. According to the topology results of these two different objectives as shown in table 1, heat dissipation and maximum temperature gradient in model 1 is smaller than model 2, and the maximum temperature in model 2 is smaller than model 1.

According to the analysis of this example, we can conclude that: the model using heat dissipation as its objective function can be used in problem which considers the homogenization of the temperature gradient; the mode using geometric average temperature as its objective function can be used in problem which considers oversize maximum temperature as its failure mode.

\section{Conclusion}

We have discussed how to minimize the highest temperature of a heat conduction structure by designing the material distribution with a specified material volume (conductivity ability). The large error sometimes occurs between the results by the usual optimization model with an objective function of the DHTPC and the theoretical optimal design. A geometric average temperature has been proposed, which is a better thermal performance index as the objective function. The solution of the new model with the geometric average temperature as the objective function is close to the theoretical optimal solution.

\section{Acknowledgment}

This work was supported by National Natural Science Foundation of China (10902019, 90816025), by the national key basic research program of china (Grant No.2011CB610304) and by the fundamental research funds for the central universities (DUT11LK07).

\section{Referencess}

Bejan A. Constructal theory network of conducting paths for cooling paths for cooling a heat generating volume. International Journal of Heat Mass Transfer1997; 40(4): 799816.

Bejan A. Shape and Structure, from Engineering to Nature. Cambridge: Cambridge University Press, 2000.

Ledezma GA, Bejan A, Errera MR. Constructal tree network for heat transfer. Journal of Applied Physics1997; 82(1): 89-100.

Almogbel M, Bejan A. Conduction trees with spacing at tips. International Journal of Heat Mass Transfer 1999; 42 (20): 3739-56.

Almogbel M, Bejan A. Constructal optimization of nonuniformly distributed tree-shaped flow structures for conduction. International Journal of Heat Mass Transfer 2001; 44 (22): 4185-94.

Rocha LAO, Lorente S, Bejan A. Constructal design for cooling a disc-shaped area by conduction. International Journal of Heat and Mass Transfer 2002; 45(8): 1643-52. 
Silva AKD, Vasile C, Bejan A. Disc cooling with high-conductivity inserts that extend inward from the perimeter. International Journal of Heat and Mass Transfer 2004; 47(19-20): 4257-63.

Rocha LAO, Lorente S, Bejan A. Conduction tree networks with loops for cooling a heat generating volume. International Journal of Heat and Mass Transfer 2006; 49(15-16): 2626-35.

Cheng XG, Xia ZZ, Li ZX, et al. Optimization of heat conduction: Thermal dissipation and optimal thermal conductivity distribution. Journal of Engineering Thermophysics 2002; 23(6): 715-17 [in Chinese].

Xia ZZ, Guo ZY. Heat conduction optimization simulated by life evolution. Progress in Natural Science 2001; 11(8): 845-52 [in Chinese].

Guo ZY, Cheng XG, Xia ZZ. Least dissipation principle of heat transport potential capacity and its application in heat conduction optimization. Chinese Science Bulletin 2003; 48(4): 406-10.

Cheng XG, Li ZX, Guo ZY. Variational principles in heat conduction. Journal of Engineering Thermophysics 2004; 25(3): 457-9 [in Chinese].

Guo ZY, Liang XG, Zhu HY. Entranspy - A new physical property of the overall capacity of heat transport. Progress in Natural Science 2006; 16(10): 1288-96 [in Chinese].

Cheng XG, Meng JA, Guo ZY. Potential capacity dissipation minimization and entropy generation minimization in heat conduction optimization. Journal of Engineering Thermophysics 2005; 6(6): 1034-6 [in Chinese].

Han GZ, Guo ZY. Two different thermal optimization objective functions: Dissipation of heat transport potential capacity and entropy production. Journal of Engineering Thermophysics 2006; 27(5): 811-3 [in Chinese].

Li Q, Steven GP, Xie YM, et al. Evolutionary topology optimization for temperature reduction of heat conducting fields. International Journal of heat mass transfer 2004; 47 (23): 5071-83.

Jia HP. Topology optimization of structure and compliant mechanism. Doctor Dissertation, Dalian University of Technology. 2004; 95-118 [in Chinese].

Zuo KT, Chen LP, Zhang YQ, et al. Structural optimal design of heat conductive body with topology optimization method. Chinese Journal of Mechanical Engineering 2005; 41(4):13-21 [in Chinese].

Zhang YC, Liu ST. Design of conducting paths based on topology optimization. Heat and Mass Transfer, online; DOI 10.1007/s00231-007-0365

Li JC, Ye BY, Tang Y, et al. Algorithm of topology optimization criteria for heat conduction structure based on density approach. Journal of South China University of Technology (Natural Science Edition) 2006; 34(2):27-32[in Chinese].

$\mathrm{Xu} \mathrm{XH}$, Liang $\mathrm{XG}$, Xun RJ. Optimization of heat conduction using combinatorial optimization algorithms. International Journal of Heat Mass Transfer 2007; 50 (9-10): 1675-82.

Francois MP, Louis G. Optimal conduction pathways for a heat generating body: a comparison exercise. International Journal of Heat Mass Transfer, 2007; 50(15-16): 2996-3006. 
Wu WJ, Chen LG, Sun FR. Improvement of tree-like network constructal method for heat conduction optimization, Science in China: Series E Technological Sciences 2006; 49(3): 1-10.

Zhou Shengbin, Chen lingen, Sun Fengrui. Optimization of constructual volume-point conduction with variable cross section conducting path. Energy Conversion and Management 2007; 48(1):106-11.

Liu MA, Dong QX, Chen S. Investigation on thermal design for opening cabinet of electronic equipment by numerical simulation. Journal of air force engineering university (natural science edition) 2005; 6(2):62-5 [in Chinese].

Qi YQ, He YL, Zhang W, et al. Thermal analysis and design of electronic equipments. Modern Electronic Technology 2003; 144:73-76 [in Chinese]. 


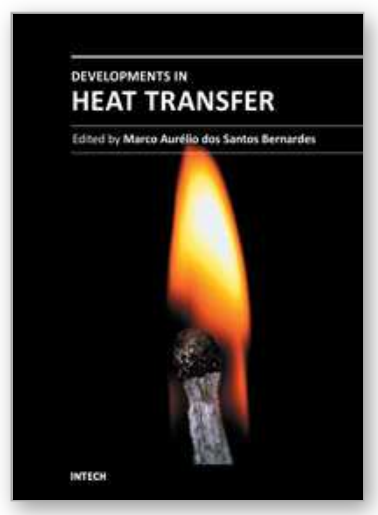

\author{
Developments in Heat Transfer \\ Edited by Dr. Marco Aurelio Dos Santos Bernardes
}

ISBN 978-953-307-569-3

Hard cover, 688 pages

Publisher InTech

Published online 15, September, 2011

Published in print edition September, 2011

This book comprises heat transfer fundamental concepts and modes (specifically conduction, convection and radiation), bioheat, entransy theory development, micro heat transfer, high temperature applications, turbulent shear flows, mass transfer, heat pipes, design optimization, medical therapies, fiber-optics, heat transfer in surfactant solutions, landmine detection, heat exchangers, radiant floor, packed bed thermal storage systems, inverse space marching method, heat transfer in short slot ducts, freezing an drying mechanisms, variable property effects in heat transfer, heat transfer in electronics and process industries, fission-track thermochronology, combustion, heat transfer in liquid metal flows, human comfort in underground mining, heat transfer on electrical discharge machining and mixing convection. The experimental and theoretical investigations, assessment and enhancement techniques illustrated here aspire to be useful for many researchers, scientists, engineers and graduate students.

\title{
How to reference
}

In order to correctly reference this scholarly work, feel free to copy and paste the following:

Yongcun Zhang, Shutian Liu and Heting Qiao (2011). Design of the Heat Conduction Structure Based on the Topology Optimization, Developments in Heat Transfer, Dr. Marco Aurelio Dos Santos Bernardes (Ed.), ISBN: 978-953-307-569-3, InTech, Available from: http://www.intechopen.com/books/developments-in-heattransfer/design-of-the-heat-conduction-structure-based-on-the-topology-optimization

\section{INTECH}

open science | open minds

\section{InTech Europe}

University Campus STeP Ri

Slavka Krautzeka 83/A

51000 Rijeka, Croatia

Phone: +385 (51) 770447

Fax: +385 (51) 686166

www.intechopen.com

\section{InTech China}

Unit 405, Office Block, Hotel Equatorial Shanghai

No.65, Yan An Road (West), Shanghai, 200040, China

中国上海市延安西路65号上海国际贵都大饭店办公楼 405 单元

Phone: +86-21-62489820

Fax: $+86-21-62489821$ 
(C) 2011 The Author(s). Licensee IntechOpen. This chapter is distributed under the terms of the Creative Commons Attribution-NonCommercialShareAlike-3.0 License, which permits use, distribution and reproduction for non-commercial purposes, provided the original is properly cited and derivative works building on this content are distributed under the same license. 